msh-mss Mathématiques et sciences humaines

155-156 | Automne-Hiver 2001

Varia

\title{
In memorian : Louis Frey
}

In memorian: Louis Frey

\section{OpenEdition}

1 Journals

Édition électronique

URL : http://journals.openedition.org/msh/3224

DOI : $10.4000 /$ msh.3224

ISSN : 1950-6821

Éditeur

Centre d'analyse et de mathématique sociales de l'EHESS

Édition imprimée

Date de publication : 1 décembre 2001

ISSN : 0987-6936

Référence électronique

"In memorian : Louis Frey », Mathématiques et sciences humaines [En ligne], 155-156 | Automne-Hiver 2001, mis en ligne le 10 février 2006, consulté le 23 juillet 2020. URL : http://journals.openedition.org/ $\mathrm{msh} / 3224$

〔c École des hautes études en sciences sociales 
Math. \& Sci. hum. (39e année, n 156, 2001, p. 5-32)

\section{AVANT-PROPOS}

Louis Frey (1924-1999) fut longtemps (et jusqu'à sa retraite) titulaire de la chaire de Logique de l'Université de Provence (section de Philosophie).

Auteur d'une thèse mémorable sur une application des mathématiques à la critique textuelle ${ }^{1}$, il s'est surtout occupé, en étroite collaboration avec le Centre de mathématique sociale de l'École des hautes études en sciences sociales, de méthodes algébriques ou combinatoires pour la modélisation mathématique dans les sciences sociales $^{2}$

Les vingt dernières années de sa vie furent principalement consacrées à une recherche originale: quelles propriétés des mathématiques connues par les contemporains de leur construction pourraient-elles éclairer, sinon expliquer, certaines proportions « harmonieuses » observées sur des édifices de l'Antiquité grecque et de l'Antiquité romaine?

L'article publié ici est inédit. Louis Frey y montre comment et pourquoi il a été amené à élaborer une théorie purement conjecturale, comme il l'a lui-même souvent souligné, mais cohérente avec les mesures prises sur des monuments d'une part, les mathématiques de leur époque d'autre part.

C'est en hommage au scientifique et à l'ami que nous publions aujourd'hui un texte où il fournit l'essentiel de sa démarche.

M.B.

\footnotetext{
${ }^{1}$ Louis Frey, Analyse ordinale des évangiles synoptiques, La Haye et Paris, Mouton et Gauthier-Villars, 1972.

${ }^{2}$ Voir notamment : Louis Frey, Techniques ordinales en analyse des données : algèbre et combinatoire, Paris, Hachette, 1971.
} 